\title{
A comparison of predatory behavior between prey-naive and prey-experienced adult coyotes (Canis latrans)
}

\author{
PAUL L. MARKSTEIN and PHILIP N. LEHNER \\ Colorado State University, Fort Collins, Colorado 80523
}

\begin{abstract}
Three adult prey-naive and three adult prey-experienced coyotes were individually presented adult rats to determine the relative roles of prey experience and maturation in prey killing and consumption. The prey-naive coyotes individually played with and eventually "accidentally" killed the rats but did not consume them. When paired, the prey-naive coyotes competed for the rats, killed them, and tore them open, exposing flesh and stimulating consummatory responses. All three prey-naive coyotes learned to kill and consume rats in the social context and later performed the behavior as individuals. The experienced coyotes quickly killed and consumed rats in a species-typical manner as individuals during their initial and subsequent two trials. It was demonstrated that play with prey is necessary for speciestypical prey killing to develop, even in mature coyotes.
\end{abstract}

Predation in mammals has been the topic of diverse behavioral studies (Kruuk, 1972; Lehner, 1976; Leyhausen, 1979; Schaller, 1972) and has been examined and discussed in relation to evolution (Eisenberg \& Leyhausen, 1972), motivation (Leyhausen, 1965), and ontogeny (Fox, 1969; Vincent \& Bekoff, 1978).

Fox (1969) characterized the prey-killing sequence of naive hand-raised coyote pups (Canis latrans) on rodent prey as a "coyote play cycle." However, Bekoff (1976) contended that uncoordinated behavior of an inexperienced animal should not be designated as play just because it failed to reach some goal as quickly as expected by the observer. Vincent and Bekoff (1978) stated that Fox's results could best be interpreted in terms of an altered version of Leyhausen's (1965) "relative hierarchy of moods." That is, "action patterns with the lowest threshold are performed first, and these appetitive actions may, instead of leading directly to consummatory behavior, lead to other appetitive actions. Since the expected goal is not attained during initial interactions with the prey, the activity can easily be interpreted as play, when in fact it is not" (Vincent \& Bekoff, 1978, p. 230). Vincent and Bekoff (1978) showed that naive coyote pups kill, although not in the species-typical manner, and they apparently learn species-typical predatory behavior through experience. Nevertheless, several deprivation studies have proven the existence of "phylogenetically adapted" behaviors, that is, behaviors that appear without apparent prior experience. For example, Eibl-Eibesfeldt (1963) isolated

We would like to thank Steve Horn for his help and cooperation throughout the study. Thanks are also extended to Marc Bekoff for his review of an earlier draft of this manuscript. Please address reprint requests to $P$. Lehner. squirrels (Sciurus vulgaris L.) and found that they mastered the entire sequence of food hiding on the first attempt. He also showed that prey catching by polecats, the shaking and turning over of the prey, occurs on the first occasion prey is given to a naive animal.

The aim of our investigation was to compare preykilling behavior in prey-naive (i.e., prey-deprived) and prey-experienced adult coyotes. The question we attempted to answer was whether coyotes that were allowed to play as they matured (but were deprived of experience with prey) would exhibit species-typical predatory behavior as adults. Thus we were testing whether maturation (exclusive of experience with prey) is a prime factor in developing coyote predatory behavior or whether prey-naive adults would develop predatory behavior in a manner similar to that found in pups.

\section{METHOD}

Six adult (sexually mature) coyotes were used in the study. The prey-naive group contained three females that were 1 year old. The preyexperienced group had three experienced males that averaged about 4 years of age. Sex differences have been shown not to be related to prey killing ability, at least in young coyotes (Vincent \& Bekoff, 1978). The prey-naive coyotes had never seen live prey before. They were hand reared, and when able to eat solids, they were fed Ranchway kibbled dog food. The prey-experienced coyotes were also hand reared, but they had all killed and eaten various-sized prey (e.g., mice, rats, rabbits, sheep) numerous times. Both groups were on a $48 \mathrm{~h}$ food-deprivation schedule when placed in the test situation, although Vincent and Bekoff (1978) had found that hunger was not related to latency to kill in juvenile coyotes. Adult laboratory rats (Rattus norvegicus) (mean weight $=417 \mathrm{~g}$ ) were used as the prey.

A $7 \times 11.5 \mathrm{ft}$ indoor enclosure was used to test the naive coyotes. Due to handling problems, trials for the experienced group were run in an isolated $12 \times 14 \mathrm{ft}$ outdoor kennel. The enclosures were new to both groups. Four different tests were 
run in the following order. Test 1: The coyotes were individually presented a live rat (two trials each). Test 2: The coyotes were individually presented with a live rat with $3 \mathrm{cc}$ of rat blood spread on its back (one trial each). This tested whether blood would stimulate killing and consumption by the prey-naive coyotes and shorten the killing latency in the preyexperienced coyotes. Test 3: The prey-naive coyotes were paired and presented a live rat (one or two trials, depending on the coyote). This tested the effect of social facilitation on killing and consumption in the prey-naive coyotes. Test 4: The prey-naive coyotes were separated and again individually presented a live rat (one to three trials, depending on the coyote). This tested for carry-over effects from the previous social facilitation test.

Tests 3 and 4 were not administered to the prey-experienced coyotes because they readily killed rats during the first two tests. The rats were presented to all of the coyotes in the same manner. They were held by the tail and placed in the center of the enclosure on all trials. Trials could last a maximum of $1 \mathrm{~h}$ but were terminated when the rat was killed and consumed or when it was apparent that killing and/or consumption would not occur (e.g., when the coyote avoided or ignored the rat completely). All the trials were recorded on videotape. The tape was analyzed by recording the behaviors according to the predefined behavioral catalog used by Vincent and Bekoff (1978). A metronome and stopwatch were used for measurements of the duration of each type of behavior. The data were then inspected and compared statistically for the two groups. Behavioral sequences were analyzed using a dyadic approach to transitional probabilities.

\section{RESULTS AND DISCUSSION}

A summary of all the trials is presented in Table 1. There were 18 separate trials for the naive coyotes, totaling $7.5 \mathrm{~h}$, and 9 trials for the experienced coyotes, lasting a total of $9.3 \mathrm{~min}$.

The quick kills by the prey-experienced coyotes on all three trials sharply contrasted with the prey-naive coyotes' behavior. Initially, the naive group did not kill at all. The first kills appeared to be "accidental." That is, the coyotes played with the rat, and their tossing the rat eventually led to its death. In the paired situation the animals were extremely competitive and fought over possession of the prey. This increased excitement stimulated both coyotes, with the kills seemingly more effective (neck bites instead of tosses), followed by the first consumptions. The naive coyotes had similar mean behavioral rates for several behaviors (Figure 1). For example, prey-biting behavior (BT) occurred most often, followed by orientations to prey (OR), tossing (TS), and extraneous behaviors (EB). The experienced coyotes (Figure 2) showed slightly more variability in their behavioral groupings (an $\mathrm{F}$ test was nonsignificant), although biting behavior again occurred most often.

Comparisons were made using chi-square association tests and analyses of variance. For the naive coyotes, the results of a chi-square test between individual trials for frequency and duration $(\mathrm{df}=18, \mathrm{p}<.05)$ were significant. When these data were grouped into the four experimental conditions, they were also significant. For the prey-experienced group, the differences in frequency were nonsignificant, but the data for duration were significant for two of the three animals. The results indicate that the behavior of the naive coyotes was highly unpredictable in both frequency and duration, but the experienced coyotes were consistent in the frequency of their behavioral measures, although the time elapsed was more variable.

An analysis of variance was performed on the naive group's data. This compared behaviors between coyotes for Trials 1, 2 (Test Condition 1), 3 (Test Condition 2), and the first trial for each coyote in Test Condition 4. Due to the method of data collection, it was only in these instances that the analysis could be applied. The results were not significantly different (.05 level) among coyotes, trials, coyote-trials, and coyote-behaviors. A significant difference ( .05 level) was found in behaviors and behavior by trial interactions. This again reflected the unpredictability of the behaviors.

When the mean data for all the behaviors (combining data over all three prey-naive coyotes) was compared across trials, it was clear that prey biting increased, sniffing decreased, and extraneous behaviors decreased as the trials progressed.

\section{Analysis of Sequences}

Sequential analysis employed a first-order Markov

Table 1

\begin{tabular}{|c|c|c|c|c|c|c|c|}
\hline \multirow[b]{2}{*}{ Test } & \multirow[b]{2}{*}{ Trial } & \multicolumn{3}{|c|}{ Prey-Naive Coyotes } & \multicolumn{3}{|c|}{ Prey-Experienced Coyotes } \\
\hline & & Coyote 2 & Coyote 4 & Coyote 5 & Coyote 1 & Coyote 3 & Coyote 6 \\
\hline 1 & $\begin{array}{l}1 \\
2\end{array}$ & $\begin{array}{l}\mathrm{NK} \\
\mathrm{K}(.16 \mathrm{~m})^{*} / \mathrm{NE}\end{array}$ & $\begin{array}{l}\text { NK } \\
\text { NK }\end{array}$ & $\begin{array}{l}\text { NK } \\
\text { NK }\end{array}$ & $\begin{array}{l}\mathrm{K}(.67 \mathrm{~m})^{* *} \\
\mathrm{~K}(.90 \mathrm{~m})\end{array}$ & $\begin{array}{l}\mathrm{K}(1.16 \mathrm{~m}) \\
\mathrm{K}(.90 \mathrm{~m})\end{array}$ & $\begin{array}{l}\mathrm{K}(.92 \mathrm{~m}) \\
\mathrm{K}(.66 \mathrm{~m})\end{array}$ \\
\hline 2 & 3 & NK & $\mathrm{K}(6.7 \mathrm{~m}) / \mathrm{NE}$ & NK & $\mathrm{K}(.50 \mathrm{~m}) / \mathrm{E}$ & $\mathrm{K}(2.08 \mathrm{~m}) / \mathrm{E}$ & $\mathrm{K}(1.90 \mathrm{~m}) / \mathrm{E}$ \\
\hline 3 & $\begin{array}{l}4 \\
5 \\
6\end{array}$ & $\mathrm{NE}$ & $\begin{array}{l}\mathrm{K}(13.0 \mathrm{~m}) / \mathrm{NE} \\
\mathrm{K}(9.4 \mathrm{~m}) / \mathrm{NE} \\
\mathrm{K}(2.5 \mathrm{~m}) / \mathrm{E} \text { (paired) }\end{array}$ & $E$ (paired) & & & \\
\hline 4 & $\begin{array}{l}7 \\
8 \\
9\end{array}$ & $\begin{array}{l}\mathrm{K}(1.7 \mathrm{~m}) / \mathrm{E} \\
\mathrm{K}(3.5 \mathrm{~m}) / \mathrm{E}\end{array}$ & $\begin{array}{l}\mathbf{K}(7.9 \mathrm{~m}) / \mathrm{NE} \\
\mathbf{K}(2.8 \mathrm{~m}) / \mathrm{E} \\
\mathbf{K}(2.3 \mathrm{~m}) / \mathrm{E}\end{array}$ & $\mathrm{K}(26.5 \mathrm{~m}) / \mathrm{E}$ & & & \\
\hline
\end{tabular}

Note $-K=$ prey killed; $N K=$ prey not killed; $E=$ prey eaten; $N E=$ prey not eaten. The time to kill the prey is given in parentheses in minutes. *Kill was determined by termination of rat vocalizations. **The prey-experienced coyotes were presented all three rats on the same day; in order to keep deprivation level constant, they were not permitted to feed on the first two trials, although they attempted to do so. 


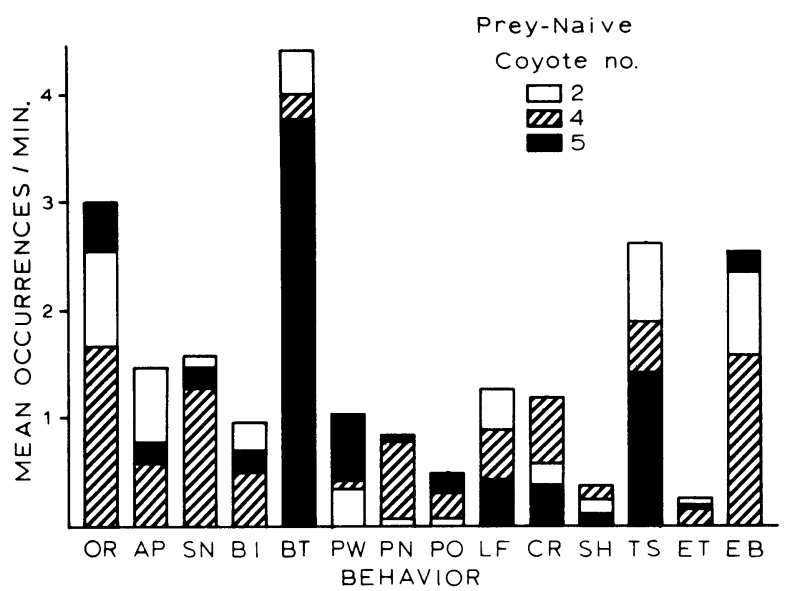

Figure 1. Mean number of occurrences per minute for all trials for each of the prey-naive coyotes' behaviors. The number of occurrences in each bar are additive. $O R=$ orientation to prey; $\mathbf{A P}=$ approach; $\mathbf{S N}=$ sniffing prey; $\mathbf{B I}=$ bite intentions; BT = prey-biting; $P W=$ pawing and stabbing prey $; \mathbf{P N}=$ pinning prey with paws; $P O=$ pouncing; $L F=$ lifting prey $\quad C R=$ carrying or dragging prey; $\mathrm{SH}=$ shaking prey; $\mathrm{TS}=$ tossing prey; ET = eating prey $; \mathrm{EB}=$ extraneous behavior not associated with predation.

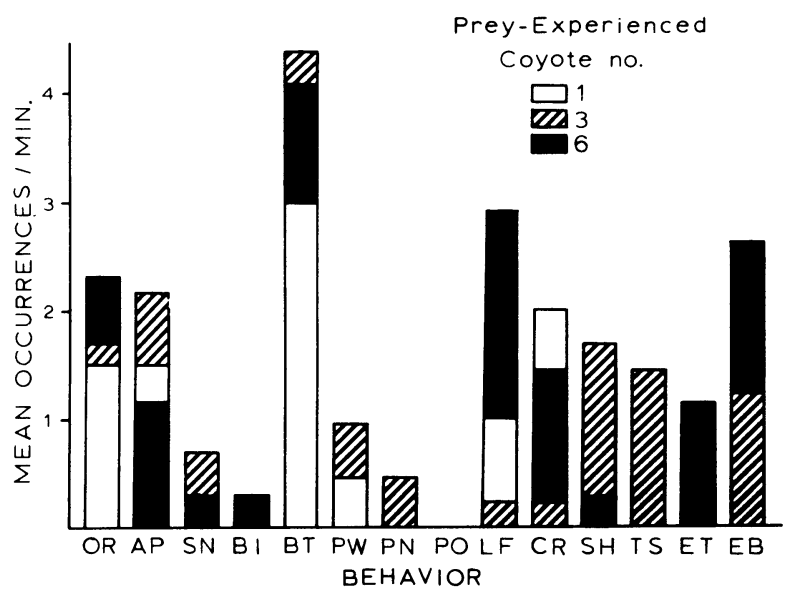

Figure 2. Mean number of occurrences per minute for all trials for each of the preyexperienced coyotes' behaviors. The number of occurrences in each bar are additive. See Figure 1 legend for behavior codes.

chain approach to transitional probabilities between any two behavioral acts. The test for sequential analysis revealed that behaviors in the early trials (Trials 1-3) of the naive group appeared random. During Trial 1 sniffing was the focal point for most behavioral patterns. In Trial 2 biting behavior became more prominent. In Trial 3 (bloodstained rats) the coyotes generally went through several sequences of orientation, bite, and toss. Pairing (Trials 4 and 6) produced many behavioral interactions. Both submissive and threat postures occurred, as did submissive whines and threat growls. In the first pairing, the subordinate coyote (Subject 4) (dominance determined previously) won a brief fight for the rat and eventually killed it. The dominant animal
(Subject 5) moved around the room constantly "eyeing" the prey. The opportunity arose for a "steal," and the dominant coyote fought for and won the rat. In the process, the rat was torn open, and Coyote 5 then proceeded to consume it while carefully watching Coyote 4. In the next trial, Coyote 4, having lost the fight for the rat in the previous trial, was individually presented a rat. She killed, but she did not eat the rat, and she centered most of her activities around bite tosses. Coyotes 4 and 2 were then paired. Once again, their behavior was intensely competitive. Coyote 4 was the subordinate animal. As in the earlier pairing, Coyote 4 won the fight for the rat. Although Coyote 2 frequently attempted to steal the prey, all attempts were unsuccessful, and Coyote 4 finally killed and ate the rat. The complicated sequences of Coyote 4 could be separated into two patterns: first, orientation, bite, lift, and carry and then extraneous behavior, approach, eat, extraneous behavior, and orientation. This demonstrated the two parts involved in the trial: killing and feeding. At the same time, Coyote 2 exhibited simple stalking behavior: orientation (looking toward), following or looking away, and orientation.

Individual trials followed the paired trials, and all three naive animals killed the rat. Most actions centered around biting behavior. During Test 4 Coyote 4's behavioral sequences were less complicated, and she resumed the orientation, bite, toss or lift, and carry pattern. Coyote 2 , upon eating a rat for the first time, performed the characteristic two-phased response, orientation, bite, toss, and bite, generally followed by orientation, eating, extraneous behavior, and orientation. Coyote 5, upon eating alone for the first time, showed new behavioral sequences. Whereas pairing produced stalking and intense competition, solitary exposure to the prey resulted in the typical orientation, bite, and toss or carry followed by an orientation, sniffing, eating, extraneous behavior, and orientation pattern terminating in consumption.

The predatory sequence for the experienced group (a combination of all nine trials) is presented in Figure 3. The trials started with an orientation to the rat, followed

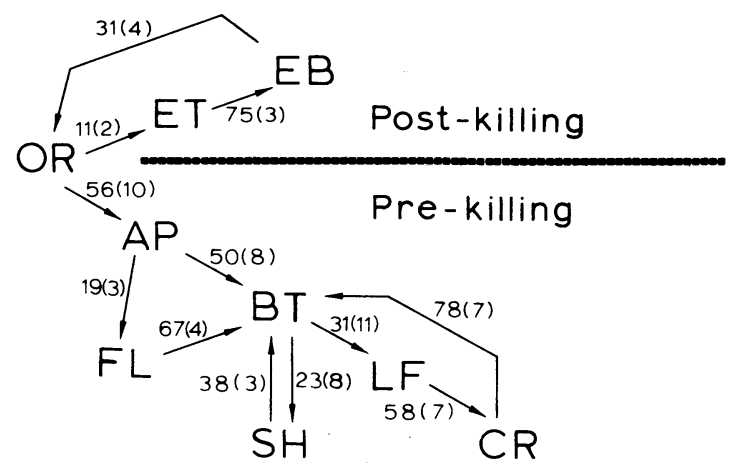

Figure 3. Composite predatory sequence for all trials for the preyexperienced coyotes. Numbers represent transitional probabilities in percent. $F L=$ following rat. See Figure 1 legend for the other behavior codes. 
by an approach. This led to biting behavior, sometimes preceded by some sniffing or following. Bites then started a cycle of bite, lift, carry, and bite, or bite, shake, and bite. Orientations after the rat was dead generally preceded eating, extraneous behavior, orientation, and eating until the prey was consumed.

The experienced coyotes killed quickly on every presentation. Certain behaviors present in the naive coyotes' sequences were not found in the experienced coyotes' patterns (i.e., chase, licking, bite intentions). The experienced animals had individually specialized killing techniques. For example, Coyote 3 always used violent head shakes that broke the rat's neck, and Coyote 6 simply applied a strong neck bite to kill. This variability may have been due to individual learning experiences and/or preferences. The speed of the experienced coyotes' kills and the deletion of specific behaviors from their prey-killing repertoire indicated efficient predation.

Individual differences remained in the killing response for the naive group, unlike the structured series of actions seen in the experienced group. As with Leyhausen's (1965) naive felids, the inexperienced coyotes were unable to quickly kill the prey, apparently because they did not bite strongly enough. Leyhausen suggested that a killing bite will only appear with heightened excitement, either through prolonged play with the prey or through additional stimulation from competing siblings; our results tend to agree.

Establishment of an operational definition for "play behavior" has been difficult (Bekoff, 1976; EiblEibesfeldt, 1975; Lazar \& Beckhorn, 1974; MullerSchwarze, 1971; Welker, 1971). Fagen (1974) maintained that the sequencing of action patterns during play is more random than nonplay behaviors, but Vincent and Bekoff (1978) caution against hastily labeling all "unstructured" behavior that does not result in a goal expected by the observer as play. Nevertheless, the unpredictable sequencing seen throughout the trials with the prey-naive coyotes, coupled with the types of behavior performed, suggests the naive group's behaviors included much play. The prey-naive coyotes that killed prey attempted prolonged play solicits toward the prey. Vincent and Bekoff (1978) also reported that play solicits correlated well with prey killing. Tail wags, pouncing leaps, and pawing appeared to be stimulated by rat movement and vocalizations, and these behaviors continued until the rat was dead. Movement is theorized to cause heightened attention and to provoke killing (Fox, 1969; Vincent \& Bekoff, 1978), and in our study movement appeared to be the primary stimulus for eliciting a play-with-prey kill. Our data reaffirmed
Fox's (1969) conclusion that blood is not a trigger for feeding by coyotes, since only one of the prey-naive coyotes killed a bloodstained rat, and that rat was not eaten. Only one of the prey-experienced coyotes had a shorter latency to kill when presented a bloodstained rat.

Our results demonstrate that prey experience is necessary in the epigenesis of prey-killing behavior in coyotes. Prey killing is not simply the result of maturation, exclusive of experience with prey. Our results support the findings of Vincent and Bekoff (1978) that playing with prey, not simply play, is a necessary prerequisite for the development of prey killing.

\section{REFERENCES}

Beкоfғ, M. Animal play: Problems and perspective. In P. Bateson \& P. Klopfer (Eds.), Perspectives in ethology (Vol. 2). New York: Plenum, 1976.

Eibl-Eibesfeldt, I. Angeborenes und Erworbenes in Verhalten einiger Sauger. Zeitschrift für Tierpsychologie, 1963, 20, 705-754.

Eibl-Eibesfeldt, I. Ethology. New York: Holt, Rinehart, \& Winston, 1975.

Eisenberg, J. F., \& Leyhausen, P. The phylogenesis of predatory behavior in mammals. Zeitschrift für Tierpsychologie, 1972, 30, 59-93.

FAGAN, R. Selective and evolutionary aspects of animal play. American Naturalist, 1974, 108, 850-858.

Fox, M. W. Ontogeny of prey-killing behavior in Canidae. Behaviour, 1969, 35, 259-272.

KRUUK, H. The spotted hyena, a study of predation and social behavior. Chicago: University of Chicago Press, 1972.

Lazar, J. W., \& Beckhorn, G. D. Social play or the development of social behavior in ferrets (Mustela putorius)? American Zoologist, 1974, 14, 405-414.

LEHNER, P. N. Coyote behavior: Implications for management. Wildlife Society Bulletin, 1976, 4, 120-126.

Leyhausen, P. Uber die Fünktion der relativen Stimmungshierarchie (dargestellt am Beispiel der phylogenetischen und ontogenetischen Entwicklung des Beutefangs von Raubtieren). Zeitschrift für Tierpsychologie, 1965, 22, 412-494.

LEYhAUSEN, P. Cat behavior: The predatory and social behavior of domestic and wild cats. New York: Garland STPM Press, 1979.

Mulle R-Schwarze, D. Ludic behavior in young mammals. In M. B. Sterman, D. J. McGinty, \& A. M. Adinolfi (Eds.), Brain development and behavior. New York: Academic Press, 1971.

Schalle r, G. B. The Serengeti lion: $A$ study of predatory-prey relations. Chicago: University of Chicago Press, 1972.

VinCENT, L. E., \& BEKoFF, M. Quantitative analyses of the ontogeny of predatory behavior in coyotes (Canis latrans). Animal Behaviour, 1978, 26, 225-231.

WELKER, W. I. Ontogeny of play and exploratory behaviors: A definition of problems and a search for new conceptual solutions. In H. Moltz (Ed.), The ontogeny of vertebrate behavior. New York: Academic Press, 1971.

(Received for publication February 18, 1980.) 